\title{
Calculation of composite elements of slabs in buildings, structures and fragments of spans of bridges
}

\author{
Stanislav Fomin ${ }^{1,}$, Yuriy Izbash ${ }^{1}$, Serhii Butenko ${ }^{1}$, Maryna Iakymenko ${ }^{1}$, and Karina \\ Spirande ${ }^{1}$ \\ ${ }^{1}$ Kharkiv National University of Construction and Architecture, 61002, Kharkiv, vul. Sumska, build. \\ 40, Ukraine
}

\begin{abstract}
The calculation consists of two stages. The first one begins with the definition of their class, bearing capacity at temperature of $20^{\circ} \mathrm{C}$, according to EN 1992-1-1. At the second stage, the calculation at high temperatures shall be carried out in accordance with Eurocode 4 part 1-2. Comparison of the "stress-strain" diagram of concrete of class 30 under compression and temperature of $20^{\circ} \mathrm{C}$ in two formulas showed their difference. That is, the designers do not have the opportunity to continue the calculation of diagrams at different heating temperatures. There was a need to improve the mathematical model of the "stress-strain" ratio of concrete high temperatures, clarification of the criteria of the bearing capacity of concrete in calculation of the fire resistance of composite structures in EN 1994-1-2:2005. In this paper, the method of determination of $\varepsilon_{c u 1, \theta}$ developed has allowed, based on the energy approach, to formulate the corrected dependence of the limit deformation on temperature, dependence of the maximum deformation on temperature, and the value of the parameters of the "stress-strain" diagram. According to these data, using the formulas of the first stage, the "stress-strain" diagrams of the concrete of class 30 are calculated at the compression and heating according to EN 1992-1-2:2004.
\end{abstract}

\section{General provision}

The calculation of the fire resistance of composite structures in the static part should take into account the following steps: the calculation of mechanical characteristics under fire conditions, the effects for thermal analysis and impacts for mechanical analysis.

Since the steel-and-reinforced concrete structures consist of reinforced concrete slabs and rolling steel beams, it is necessary to know the complete "stress-strain" diagrams of concrete, reinforcement and rolling beams to calculate their fire resistance.

Steel girders, which work together with reinforced concrete slabs, are widely used in bridge building.

\footnotetext{
* Corresponding author: sfomin@ukr.net
} 


\section{Improvement of mathematical model of deformation diagram of compressed concrete of steel-and-reinforced concrete structures under heating}

The paper [1] describes defects in the strength and deformation properties of concrete at higher temperatures that are given in EN 1994-1-2:2005 Eurocode 4, which during harmonization were included in DSTU-N-P B B.2.6-159:2010. The method of determination of the specified diagrams " $\sigma_{c, \theta}-\varepsilon_{c, \theta}$ " for the design of steel reinforced concrete structures under the fire conditions was developed. The values of the parameters of the diagram for concrete based on silicate filler at higher temperatures were specified, and the mathematical model of the "stress-strain" ratio of the concrete at compression and higher temperatures was refined.

Despite such a significant refinement of the mathematical model of the "stress-strain" diagram of concrete under compression and higher temperatures, designers do not have sufficient information to calculate the fire resistance of the structure.

The calculation of elements of reinforced concrete and composite structures consists of two stages. The first stage begins with determination of their bearing capacity at a normal temperature of $20^{\circ} \mathrm{C}$, that is, when using Eurocode 2 EN 1992-1-1:2005 [2] or DBN V.2.6-98:2009 [3]. These standards propose to use two equations to describe the relationship between $\sigma_{c}$ and $\varepsilon_{c}$ for short-term axial load. Equation (1) that is used in Eurocode 2 EN 1992-1-1:2005 [2]:

$$
\frac{\sigma_{c}}{f_{c m}}=\frac{k \eta-\eta^{2}}{1+(k-2) \eta}
$$

where $\eta=\varepsilon_{c} / \varepsilon_{c 1}, \varepsilon_{c 1}$ - deformations at maximum loads according to table 1, $k=1.05 E_{c m}\left|e_{c 1, c d}\right| / f_{c m}\left(f_{c m}\right.$ - according to table [2]);

and equation (2) in the form of a quintal polynomial, which is based on the results of numerous experimental researches of the State Research Institute of Building Structures, the statistical processing of which allowed to propose a more complete normative basis:

$$
\sigma_{c}=f_{(c k),(c d)} \sum_{k=1}^{5} \alpha_{k} \eta^{k}
$$

For both formulas, use limits were defined:

$$
0<\left|\varepsilon_{c}\right|<\left|\varepsilon_{c u 1}\right|
$$

where $\varepsilon_{c u 1}$ - nominal boundary deformations of concrete.

The paper [1] also shows that graphs practically coincide on the ascending branch according to DBN and EN92-1-1. Both normative documents contain the concrete classes, values of the relative deformation of the compression of concrete $\varepsilon_{c 1}$ at maximum stresses $f_{c}$, nominal boundary deformations of concrete $\varepsilon_{c u 1}$ (the value of relative boundary deformation of concrete compression) and the mean value of the initial elastic modulus of concrete $E_{c m}(\mathrm{GPa})$. The data given in tables 1 and 2 is sufficient for the calculation of reinforced concrete structures at a temperature of $20^{\circ} \mathrm{C}$.

So, using the base Eurocode 2 EN 1992-1-1:2005 or the national building codes of Ukraine DBN V.2.6-98:2009, which take into account the main provisions (principles) of 
Eurocode 2 EN 1992-1-1:2005, the calculations of reinforced concrete structures at temperature $20^{\circ} \mathrm{C}$ are conducted.

Table 1. Classes of concrete strength according to Eurocode 2 EN 1992-1-1:2005.

\begin{tabular}{|l|c|c|c|c|c|c|c|c|c|c|c|c|c|c|}
\hline $\begin{array}{l}f_{\text {ck }, \text { cube }} \\
(\mathrm{MPa})\end{array}$ & 15 & 20 & 25 & 30 & 37 & 45 & 50 & 55 & 60 & 67 & 75 & 85 & 95 & 105 \\
\hline$\varepsilon_{\mathrm{c} 1}(\%)$ & 1.8 & 1.9 & 2.0 & 2.1 & 2.2 & 2.25 & 2.3 & 2.4 & 2.45 & 2.5 & 2.6 & 2.7 & 2.8 & 2.8 \\
\hline$\varepsilon_{\mathrm{cu} 1}(\%)$ & 3.5 & 3.5 & 3.5 & 3.5 & 3.5 & 3.5 & 3.5 & 3.5 & 3.5 & 3.2 & 3.0 & 2.8 & 2.8 & 2.8 \\
\hline$E_{\mathrm{cm}}(\mathrm{GPa})$ & 27 & 29 & 30 & 31 & 33 & 34 & 35 & 36 & 37 & 38 & 39 & 41 & 42 & 44 \\
\hline
\end{tabular}

Table 2. The concrete strength classes according to DBN B.2.6-98:2009.

\begin{tabular}{|l|c|c|c|c|c|c|c|c|c|c|c|}
\hline & $\begin{array}{c}\mathrm{C} \\
8 / 10\end{array}$ & $\begin{array}{c}\mathrm{C} \\
12 / 15\end{array}$ & $\begin{array}{c}\mathrm{C} \\
16 / 20\end{array}$ & $\begin{array}{c}\mathrm{C} \\
20 / 25\end{array}$ & $\begin{array}{c}\mathrm{C} \\
25 / 30\end{array}$ & $\begin{array}{c}\mathrm{C} \\
30 / 35\end{array}$ & $\begin{array}{c}\mathrm{C} \\
32 / 40\end{array}$ & $\begin{array}{c}\mathrm{C} \\
35 / 45\end{array}$ & $\begin{array}{c}\mathrm{C} \\
40 / 50\end{array}$ & $\begin{array}{c}\mathrm{C} \\
45 / 55\end{array}$ & $\begin{array}{c}\mathrm{C} 50 / 6 \\
0\end{array}$ \\
\hline $\begin{array}{l}f_{\text {ck,cube }} \\
(\mathrm{MPa})\end{array}$ & 10 & 15 & 20 & 25 & 30 & 35 & 40 & 45 & 50 & 55 & 60 \\
\hline $\begin{array}{l}\varepsilon_{\mathrm{cl}, \mathrm{cd}} \\
(\% \mathrm{o})\end{array}$ & 1.56 & 1.58 & 1.62 & 1.65 & 1.69 & 1.72 & 1.76 & 1.80 & 1.84 & 1.87 & 1.91 \\
\hline $\begin{array}{l}\varepsilon_{\mathrm{cu} 1, \mathrm{~cd}} \\
(\% \mathrm{o})\end{array}$ & 3.75 & 3.70 & 3.59 & 3.44 & 3.28 & 3.10 & 2.93 & 2.72 & 2.57 & 2.43 & 2.29 \\
\hline $\begin{array}{l}E_{c m} \\
(\mathrm{GPa})\end{array}$ & 18 & 23 & 27 & 30 & 32.5 & 34.5 & 36 & 37.5 & 39 & 39.5 & 40 \\
\hline
\end{tabular}

Simultaneously, the concrete strength classes, deformation of concrete under compression $\varepsilon_{\mathrm{c} 1}$ at maximum stresses $f_{c}$, nominal limit deformations of concrete $\varepsilon_{\mathrm{cul}}$, mean value of the initial elastic modulus of concrete $E_{c m}$ and complete diagram of stress-strain of concrete were determined.

For example, for concrete strength class 30 according to Eurocode 2 EN 1992-1-1, the concrete deformations at maximum stresses $f_{c}=30 \mathrm{MPa}$ are equal to $\varepsilon_{c 1}=2.1 \%$, nominal limit deformations of concrete $-\varepsilon_{c u 1}=3.5 \%$, mean value of the initial modulus of elasticity of concrete $E_{c m}=31 \mathrm{GPa}$, and complete "stress-strain" diagram of concrete shall be determined by the formula (1).

For concrete strength class C 30/35 according to DBN V.2.6-98, the concrete deformation $f_{c}=35 \mathrm{MPa}$ are equal to $\varepsilon_{c 1}=1.72 \%$, nominal limit deformations of concrete $-\varepsilon_{c u 1}=3.1 \%$, mean value of the initial modulus of elasticity of concrete $E_{c m}=34.5 \mathrm{GPa}$, and complete "stress-strain" diagram of concrete shall be determined by the formula (2).

If the calculation showed the necessity of the strength class of concrete 30 according to Eurocode 2 EN 1992-1-1, the deformation of the concrete at maximum stresses $f_{c}=30 \mathrm{MPa}$ are equal to $\varepsilon_{c 1}=0.0021=2,1 \%$, the limit deformation of the concrete $\varepsilon_{c u 1}=0.0035=3.5 \%$, concrete elastic modulus $E_{c m}=31 \mathrm{GPa}=31.000 \mathrm{MPa}$, complete "strain-deformation" diagram of concrete at a temperature of $20^{\circ} \mathrm{C}$ shall be determined by the formula (1).

\subsection{Analysis of recent research}


In the course of the study [4], a method for determination of the criterion of concrete bearing capacity $\varepsilon_{c 1, \theta}$ was developed for calculation of the fire resistance of reinforced concrete structures, on the basis of which data of characteristics of strength and deformation properties of concrete at higher temperatures given in Eurocodes EN 1992-1-2:2004 [9] and ENV 1992-1-2:2005 Eurocode 2 were refined. The comparison of the diagram for DBN B.2.6-98 [3] at the normal temperature (2) with a similar standard diagram [5] on the ascending branch for $\varepsilon \leq \varepsilon \leq \varepsilon_{c 1, \theta}$ the diagram under the formula (4) shows a significant overstatement of the value $\varepsilon_{c u 1, \theta=20^{\circ} \mathrm{C}}=0.0200=20 \%$ (on the [3] $\varepsilon_{c u 1, c k}=2.4 \ldots 4.5 \%$ depending on the concrete class).

$$
\sigma_{c, \theta}=f_{c, \theta}\left[3\left(\frac{\varepsilon_{c, \theta}}{\varepsilon_{c u, \theta}}\right) /\left\{2+\left(\frac{\boldsymbol{\varepsilon}_{c, \theta}}{\boldsymbol{\varepsilon}_{c u, \theta}}\right)^{3}\right\}\right]
$$

Is is shown that these diagrams are obtained on special presses equipped with a heating device and a servo-control of pressure in the press cylinder, which allows passing through the descending branch practically zero stress. In this case, the branch descending to zero is no longer the area of deformation of the integral concrete sample, but the area of deformation of individual parts of the fragmented concrete. So, the values of deformations in columns 4 and 7 of Table 3.1 [5] are not limit deformations of concrete $\varepsilon_{c u l, \theta}$. The deformations $\varepsilon_{c 1, \theta}$ in this table are taken to be the same for all classes of concrete, including for silicate (column 4) and carbonate (column 7) fillers. So, depending on the class of concrete in formula (4), it is possible to vary only the value of compressive strength $f_{c}$, therefore these diagrams, even on the ascending branch, incorrectly represent the actual properties of the physical nonlinearity.

Fig. 1 shows a "stress-strain" diagram of concrete of class 30 under the formula (1) in comparison with the formula (4).

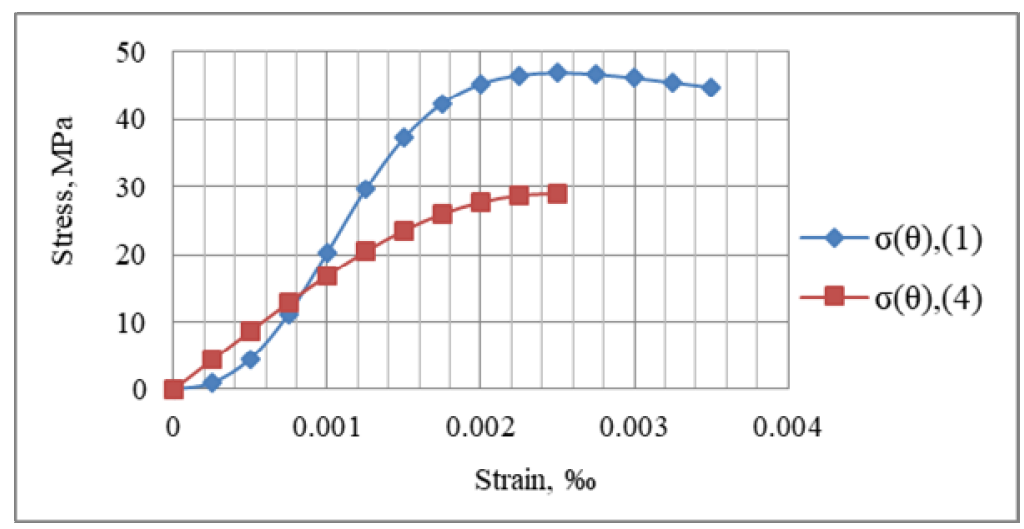

Fig. 1. The "stress-strain" diagram of concrete of class 30 under compression and temperature of $20{ }^{\circ} \mathrm{C}$ by formula (1) and (4).

This difference between the diagrams occurs because of the class of concrete is not taken into account. That is, there is no possibility for designers to continue the calculation of diagrams at different heating temperatures because they are offered a new algorithm with the absence of the concrete classes, criterion of the bearing capacity of concrete $\varepsilon_{\mathrm{cu} 1,0}$ of the elasticity of concrete $E_{c m}$, new characteristics of concrete based on a silicate and carbonate 
filler, and so on.

The defects in the standard DSTU-N-P B V.2.6-159:2010 (EN 1994-1-2:2005 Eurocode 4. MOD) [7], [8] harmonized with EN 1994-1-2:2005 [6] are also found.

So, it is necessary to improve the mathematical model of the "stress-strain" ratio of concrete under compression and elevated temperatures, refinement of the criteria of the bearing capacity of concrete when calculating the fire resistance of composite structures in EN 1994-1-2:2005.

\subsection{Results of theoretical studies}

Section 3 of the standard [5] states that the strength and mechanical properties of concrete at higher temperatures can be determined from the stress-strain dependencies given in EN 1992-1-2 [7].

In fact, the deformations $\varepsilon_{c 1, \theta}$ given in Table 3.1 are taken to be the same for all classes of concrete, including for silicate (column 4) and carbonate (column 7) fillers. So, depending on the class of concrete in formula (4), it is possible to vary only the value of compressive strength $f_{c}$, therefore these diagrams, even on the ascending branch, incorrectly represent the actual properties of the physical nonlinearity.

Eurocode EN 1992-1-2:2004 is definitely the leading normative document in the theory of concrete, reinforced concrete and composite structures, their fire resistance, and is based on high-level experiments, with new test devices, which allowed the implementation of progressive nonlinear computational models.

At the same time, the main results of the conducted studies are not consistent with the basic Eurocode 2 EN 1992-1-1:2005 [2]: Design of reinforced concrete structures Part 1-1: General norms and rules for structures, that is shown, for example, by comparing deformation diagrams at a temperature of $20^{\circ} \mathrm{C}$ and other parameters.

The correction in the indicated tables and the method for determination $\varepsilon_{c u 1, \theta}$ on the basis of the energy approach [10] have made it possible to formulate the corrected dependence of the limit deformation on temperature (Fig. 2), the dependence of the maximum deformation on temperature (Fig. 3) and Table 3 - Value of the parameters of the "stress-strain" diagram.

According to these data, using the formula (1), the "stress-strain" diagrams of concrete of class 30 were calculated under compression and heating according to EN 1992-1-2:2004 (Fig. 3).

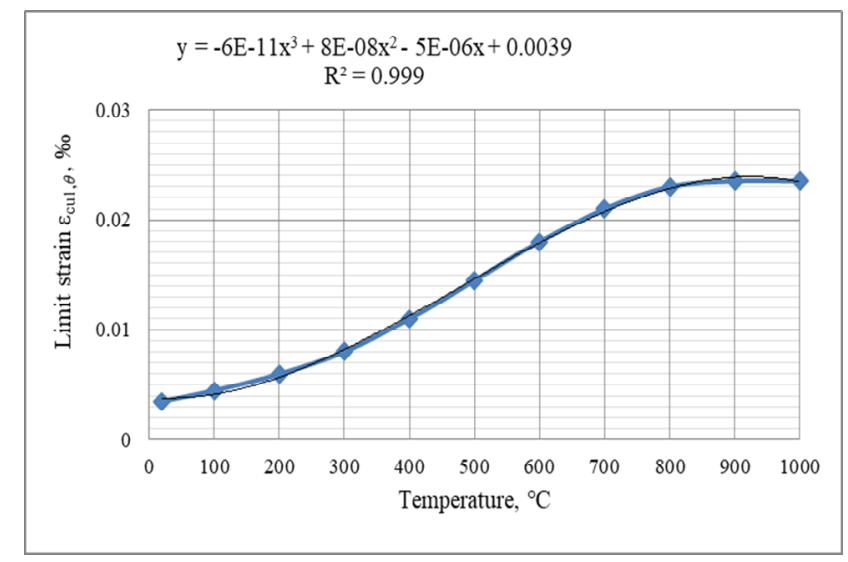

Fig. 2. The dependence of the limit deformation on temperature was adjusted. 


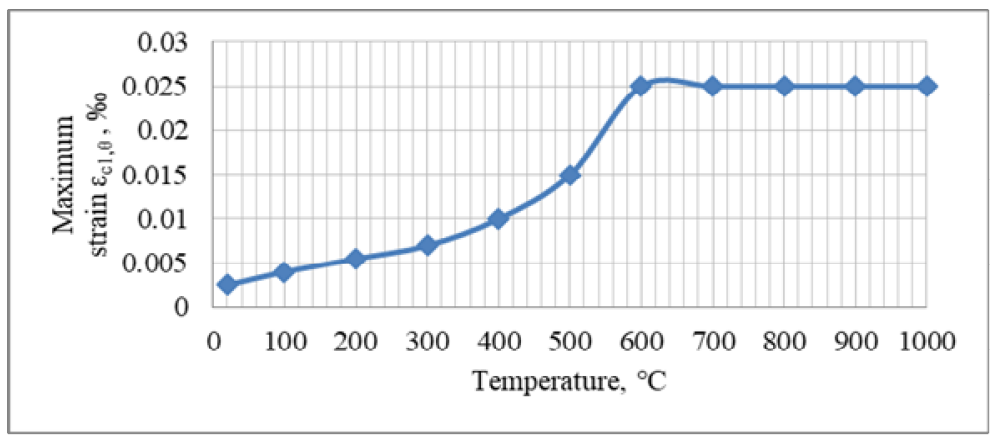

Fig. 3. The dependence of the maximum deformation on temperature.

Table 3. - The value of parameters of the "stress-strain" diagram for silicate filler based concrete at higher temperatures.

\begin{tabular}{|l|c|c|c|c|c|c|}
\hline $\begin{array}{l}\text { Concrete } \\
\text { temperature } \theta,{ }^{\circ} \mathrm{C}\end{array}$ & \multicolumn{5}{|c|}{ Silicate filler } \\
& \multicolumn{7}{|l|}{$f_{\mathrm{c}, \theta} / f_{\mathrm{ck}}$} & $\varepsilon_{\mathrm{c} 1, \theta}$ & $\varepsilon_{\mathrm{cu} 1, \theta}$ & $f_{\mathrm{c}, \theta}, \mathrm{MPa}$ & $E_{\mathrm{m} \theta, \mathrm{MPa}}$ & $E_{\mathrm{m}} / E_{c, \Theta}$ \\
\hline 20 & 1 & 0.0025 & 0.0035 & 30 & 31000 & 1 \\
\hline 100 & 1 & 0.004 & 0.0045 & & 21328 & 0.688 \\
\hline 200 & 0.95 & 0.0055 & 0.006 & & 15283 & 0.493 \\
\hline 300 & 0.85 & 0.007 & 0.008 & & 11067 & 0.357 \\
\hline 400 & 0.75 & 0.01 & 0.011 & & 7812 & 0.252 \\
\hline 500 & 0.6 & 0.015 & 0.0145 & & 4805 & 0.155 \\
\hline 600 & 0.45 & 0.025 & 0.018 & & 2790 & 0.09 \\
\hline 700 & 0.3 & 0.025 & 0.021 & & 1705 & 0.055 \\
\hline 800 & 0.15 & 0.025 & 0.023 & & 868 & 0.028 \\
\hline 900 & 0.08 & 0.025 & 0.0235 & & 536.3 & 0.0173 \\
\hline 1000 & 0.04 & 0.025 & 0.0235 & & 127.1 & 0.0041 \\
\hline
\end{tabular}




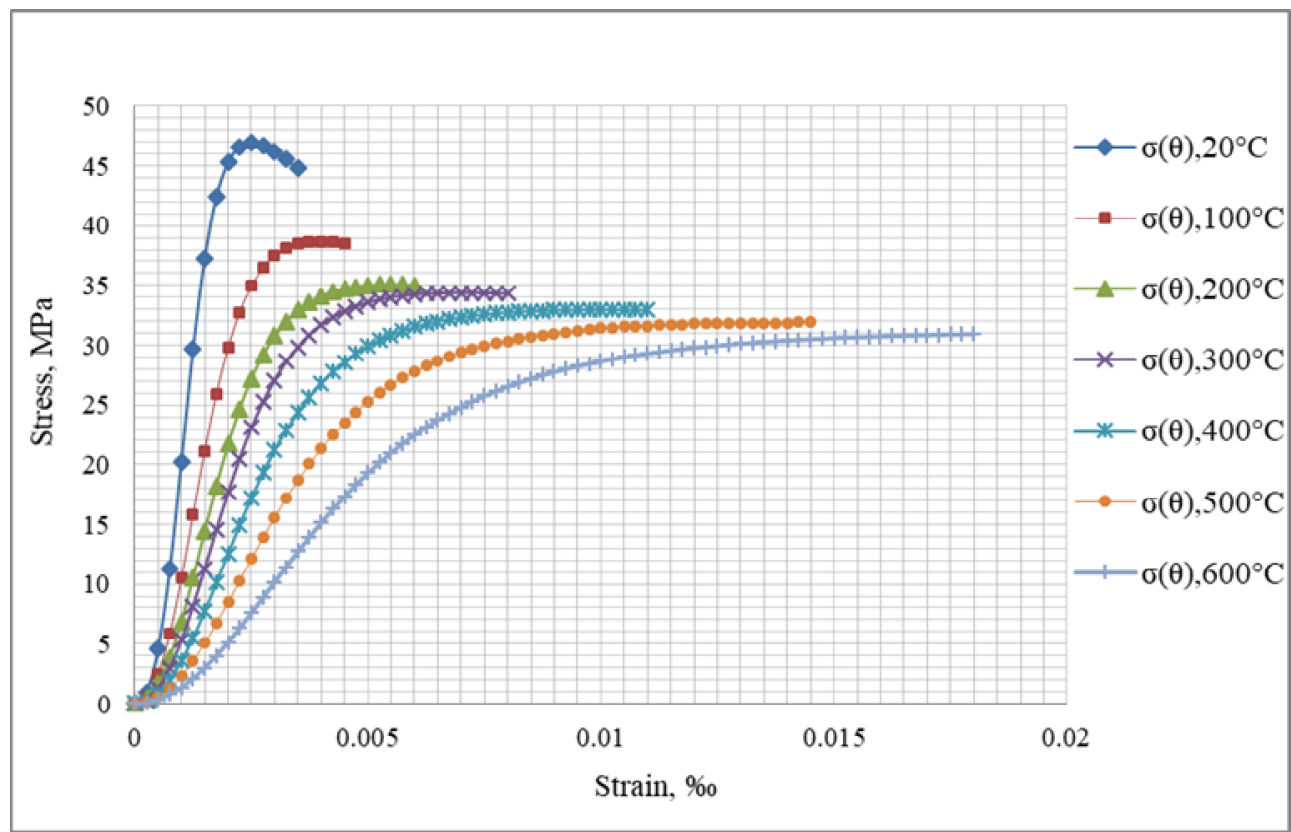

Fig. 4. Stress-strain diagrams of concrete of class 30 under compression and heating according to Eurocode EN 1992-1-2:2004.

\section{Conclusions}

1. The paper [1] revealed defects in strength and deformation properties of concrete at higher temperatures given in EN 1994-1-2:2005 Eurocode 4. Despite the refinement of the mathematical model of the "stress-strain" diagram of concrete under compression and higher temperatures, the designers lack information to fully calculate the fire resistance of the structure.

2. It is shown that the calculation of elements of reinforced concrete and composite structures consists of two stages. The first stage begins with determination of their bearing capacity at a normal temperature of $20^{\circ} \mathrm{C}$, that is, when using Eurocode 2 EN 1992-1-1:2005 [2] or DBN V.2.6-98:2009 [3]. These standards propose to use two equations to describe the relationship between $\sigma_{c}$ and $\varepsilon_{c}$ for short-term axial load. Equation (1), which is used in Eurocode 2 EN 1992-1-1:2005 [2], and equation (2) in the form of quintal polynomial, which is based on the results of numerous experimental researches of the National State Institute of Concrete Structures (NSICS), the statistical processing of which allowed to offer a more complete normative base.

3. In the course of the study [4], a method for determination of the criterion of concrete bearing capacity $\varepsilon_{c u 1, \theta}$ was developed for calculation of the fire resistance of reinforced concrete structures, on the basis of which data of characteristics of strength and deformation properties of concrete at higher temperatures given in Eurocodes EN 1992-1-2:2004 and ENV 1992-1-2:2005 Eurocode 2 were refined. The comparison of the diagram according to DBN B.2.6-98 [3] at the normal temperature (2) with a similar diagram of the standard [5] on the ascending branch at $\varepsilon \leq \varepsilon_{c 1, \theta}$ for the diagram under the formula (4) shows a significant overstatement of the value 
$\varepsilon_{c u 1, \theta=20^{\circ} \mathrm{C}}=0.0200=20 \%$ (on the [5] $\varepsilon_{c u 1, c k}=2.4 \ldots 4.5 \%$ depending on the concrete class).

4. The "stress-strain" diagram of concrete of class 30 under compression and temperature of $20^{\circ} \mathrm{C}$ by formula (1) compared with formula (4) showed a large difference: at $\varepsilon_{c}=0.0025$ by the formula (1) $\sigma_{c}=47 \mathrm{MPa}$ by the formula (4) $\sigma_{c}=28 \mathrm{MPa}$. This difference between diagrams occurs due that the concrete class is not taken into account. That is, there is no possibility for designers to continue the calculation of diagrams at different heating temperatures because they are offered a new algorithm with the absence of the concrete classes, criterion of the bearing capacity of concrete $\varepsilon_{\mathrm{cul}, 0}$ of the elasticity of concrete $E_{c m}$, new characteristics of concrete based on a silicate and carbonate filler, and so on. The defects in the standard DSTU-N-P B V.2.6-159:2010 (EN 1994-1-2:2005, Eurocode 4. MOD) [7] harmonized with EN 1994-1-2:2005 were also identified.

5. The table of values of parameters of the "stress-strain" diagram for silicate-based concrete at higher temperatures was developed.

6. The correction in the indicated tables and the method for determination $\varepsilon_{\mathrm{cu} 1, \theta}$ on the basis of the energy approach [10] have made it possible to formulate the corrected dependence of the limit deformation on temperature (Fig. 2), the dependence of the maximum strain on temperature (Fig. 3) and Table 3 - Value of the parameters of the "stress-strain" diagram.

According to these data, using the formula (1), the "stress-strain" diagrams of concrete of class 30 were calculated under compression and heating according to EN 1992-1-2: 2004 (fig. 4).

\section{References}

1. S. Fomin, Y. Izbash, I. Plakhotnikova, S. Butenko and R. Shemet, MATEC Web of Conferences, 116, 02013, 4 (2017)

2. EN 1992-1-1:2005 Eurocode 2: Design of reinforced concrete structures - Part 1-1: General norms and rules for structures, 136 (2005)

3. DBN V.2.6-98:2009 Structures of buildings and facilities. Concrete and reinforced concrete structures. Basic provisions. Ministry of regional development and construction of Ukraine, Kiev, 71 (2011)

4. S.L. Fomin, A.I. Davidenko, V.G. Poklonsky, News of Odessa State Academy of construction and architecture, 46, 8 (2012)

5. DSTU-N-P B V.2.6-159:2010 Structures of buildings and facilities. Design of composite steel and concrete structures. Part 1-2. General provisions. Structural fire design. (EN 1994-1-2:2005, Eurocode 4. MOD), 37 (2010)

6. ENV 1992-1-2:1995 Eurocode 2: Design of Concrete Structures - Part 1-2: General Rules - Structural Fire Design, 82 (1995)

7. DSTU-N B EN 1992-1-2:2012. Eurocode 2: Design of concrete structures. Part 1-2: General rules. Structural fire design. (EN 1992-1-2:2004, IDT). Minregionbud of Ukraine, Kiev, 131 (2012)

8. DBN V.2.6-160:2010 Composite steel and concrete structures. Basic provisions. Minregionbud of Ukraine, Kiev, 55 (2011)

9. EN 1992-1-2: 2004 Eurocode 2: Design of concrete structures - Part 1-2: General rules - Structural fire design, 75 (2004)

10. A.N. Bambura, First Ukr. Sc. Tech. Conf., Scientific - practical problems of modern concrete, 36, 7 (1996) 